\title{
Impact of pre-harvest rainfall on the distribution of fusarium mycotoxins in wheat mill fractions
}

by Edwards, S.G., Kharkibar, L.L., Dickin, E.T., MacDonald, S., and Scudamore, K.A.

Copyright, Publisher and Additional Information: This is the author accepted manuscript. The final published version (version of record) is available online via Elsevier.

This version is made available under the CC-BY-ND-NC licence:

https://creativecommons.org/licenses/by-nc-nd/4.0/legalcode

Please refer to any applicable terms of use of the publisher

DOI: https://doi.org/10.1016/i.foodcont.2018.02.009

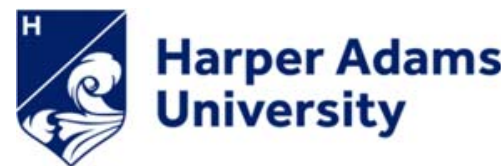

Edwards, S.G., Kharkibar, L.L., Dickin, E.T., MacDonald, S., and Scudamore, K.A. 2018. Impact of preharvest rainfall on the distribution of fusarium mycotoxins in wheat mill fractions. Food Control. 
1 Impact of pre-harvest rainfall on the distribution of fusarium mycotoxins in

2 wheat mill fractions

3 Simon G. Edwards ${ }^{1 *}$, Lalit L. Kharbikar ${ }^{1 \dagger}$, Edward T. Dickin ${ }^{1}$, Susan MacDonald ${ }^{2}$ and Keith A.

4 Scudamore ${ }^{3 \S}$

$6 \quad{ }^{1}$ Harper Adams University, Newport, Shropshire, TF10 8NB, UK; ${ }^{2}$ Fera Science Ltd, Sand Hutton,

7 York YO41 1LZ, UK; ${ }^{3}$ KAS Mycotoxins, 6 Fern Drive, Taplow, Maidenhead, SL6 0JS, UK

9 *Corresponding author. E-mail address: sedwards@ harper-adams.ac.uk (Simon Edwards)

10 Present address: ICAR - National Institute of Biotic Stress Management, Raipur, 493 225, India

$11{ }^{\S}$ Retired

12

13 Legislative limits for Fusarium mycotoxins decrease from unprocessed wheat to processed

14 products. A previous observational study identified a seasonal difference in the distribution of DON

15 but not ZON within mill fractions. Rainfall is known to influence the production of these

16 mycotoxins in wheat, but the effects of rainfall on their distribution within mill fractions is not

17 known. Laboratory and field experiments were conducted to determine the impact of different

18 watering regimes on the distribution of DON and $\mathrm{ZON}$ in wheat mill fractions. Results indicated

19 that repeated wetting and drying could cause movement of DON towards equilibrium across the

20 mill fractions. Whereas, high levels of rainfall could cause a large reduction of DON in the grain,

21 predominantly from the bran fraction, resulting in a proportional increase within white flour. ZON

22 was detectable in fewer samples but results indicated it is less mobile within the grain. It is

23 important for processors to be aware of the variation of mycotoxin distribution within mill fractions

24 and the drivers of this variation to ensure limits set for grain intake result in mill products within

25 mycotoxin legislative limits.

26

27 Keywords: fusarium; mycotoxin; deoxynivalenol; zearalenone; wheat; milling; flour; bran; offal;

28 water 
Fusarium mycotoxins of particular concern in wheat and other small grain cereals are deoxynivalenol (DON) and zearalenone (ZON) (Edwards, 2009). Wheat is mostly consumed after processing: wheat grains are cleaned, conditioned by the addition of water and dry milled (primary processing) to intermediary products; bran, offal (mix of fine bran and germ) and white flour, for direct consumption or further processing (secondary processing). Being major contaminants in Fusarium infected wheat, mycotoxins are regulated in unprocessed grain and intermediary products as well as processed products of wheat through legislation. The European legislative limits for DON and ZON decrease from unprocessed wheat (1250 and $100 \mu \mathrm{g} \mathrm{kg}^{-1}$, respectively), through intermediate products such as flour and bran (750 and $75 \mu \mathrm{g} \mathrm{kg}^{-1}$, respectively), to finished products such as wheat snacks and breads (500 and $50 \mu \mathrm{g} \mathrm{kg}^{-1}$, respectively) (EC, 2006). However, it is known that mycotoxins are predominantly located in the outer layers of grain and as such high fibre/bran based products can have equivalent or higher concentrations of mycotoxins than the original unprocessed wheat (Scudamore, Hazel, Patel, \& Scriven, 2009; Scudamore \& Patel, 2008). It is important for processors to understand the distribution of mycotoxins after processing and the variability within this relationship and factors that impact upon it so they can, if necessary, set trade limits at intake to ensure their products conform to the legal limits.

Studies in several countries, using a range of varieties and different mills have identified that after milling there is a lower proportion of DON within the white flour fractions and higher proportion in the bran and offal fractions. The impact of dry milling of wheat on deoxynivalenol was reviewed by (Cheli, Pinotti, Rossi, \& Dell'Orto, 2013) and (Kushiro, 2008) and subsequently reported in more recent publications (Brera, et al., 2013; Fernandes, Barros, Santo, \& Camara, 2015; Savi, et al., 2016; Schwake-Anduschus, et al., 2015; Tibola, Fernandes, Guarienti, \& Nicolau, 2015; Zhang \& Wang, 2014; Zheng, et al., 2014). Typical concentrations in white flour are 50-80\% of the cleaned grain DON concentration. Some studies have shown that the distribution of mycotoxins varied with mycotoxin concentration of the grain, and that white flour derived from the endosperm of highly contaminated grains had a greater proportion of the DON compared with less contaminated grains (Edwards, et al., 2011; Thammawong, et al., 2010; Tibola, et al., 2015). A two-year observational study in the UK identified seasonal differences in the distribution of DON within the grain (Edwards, et al., 2011). Using the concentration of ergosterol as an indicator of fungal biomass, (Thammawong, et al., 2011) showed that fungal growth was largely restricted to the outer layers of the grain, but that 61 mycotoxins diffused into the endosperm. The level of diffusion into the grain was independent of the 62 level of fungal invasion, implying that environmental conditions post-infection will have a role in 63 determining mycotoxin levels in milling fractions. In support of this conclusion, DON concentration 64 was higher in white flour than in bran obtained from UK wheat samples in 2004, when high postanthesis rainfall was recorded (Edwards, et al., 2011). DON is highly water-soluble (Karlovsky, et 
al., 2016) and can be translocated within host plants (Moretti, et al., 2014) and it was proposed that the high pre-harvest rainfall in UK in 2004 caused the movement of DON within grain. Other studies have indicated that the overall DON concentration of grain is impacted by post-anthesis rainfall with evidence that DON can be leached from the grain (Gautam \& Dill-Macky, 2012a). A recent study has also shown a large shift in DON concentrations for different ear structures (rachis, grain and glumes) during the post-anthesis period (Cowger \& Arellano, 2013). Fewer previous studies have investigated the effects of milling on distribution of ZON. Where studied, the distribution of ZON was less variable than DON and was consistently higher in the bran and offal fractions and lower in white flour fractions (Schwake-Anduschus, et al., 2015; TrigoStockli, Deyoe, Satumbaga, \& Pedersen, 1996; Zheng, et al., 2014) and no significant seasonal differences in the distribution of ZON were observed (Edwards, et al., 2011).

The impact of rainfall on the distribution of mycotoxins in mill fractions has not been investigated experimentally. Laboratory and field experiments were designed to understand the impact of pre-harvest rainfall and harvest time on the distribution of Fusarium mycotoxins in wheat mill fractions. Laboratory experiments included repeated conditioning (wetting and drying) to simulate wet harvest conditions and washing of grain with a water sprinkler to mimic heavy rainfall. Field experiments used mist irrigation and sprinkler irrigation to simulate similar wetting events.

\section{Materials and Methods}

Wheat samples were sourced with moderate to high DON from farm stores based on samples analyzed as part of a previous study (Edwards, 2009). The aim was to obtain wheat samples that may enter a mill for processing wheat for human consumption, based on quality parameters and appearance, although some exceeded the DON legal limit for wheat intended for human consumption $\left(1250 \mu \mathrm{g} \mathrm{kg}^{-1}\right)$. Two extremes of in vitro water treatment were used: 1$)$ repeated conditioning (wetting and drying) of grain; 2) washing of grain. Four different wheat samples (7 kg lots) were used for each treatment (Table 1). Subsequently field experiments were performed with mist and sprinkler irrigation of winter wheat crops infected with Fusarium spp. during or after ripening.

\subsection{Repeated conditioning $(C)$ of wheat from 15 to $25 \%$ moisture content.}

For each lot of wheat the moisture content was measured and volume of water to adjust the grain moisture content to $25 \%$ was calculated and applied to grain with a hand-held sprayer while mixing in a cement mixer. Grain was placed in a plastic bag, tied and stored at $4^{\circ} \mathrm{C}$ for three days. Grain was mixed once each day, after 3 days grain was dried on a hot-air dryer until the moisture content was ca. $15 \%$ (ca. 16 hours). Grain was stored for one day at room temperature to allow moisture 
content to reach equilibrium before the conditioning was repeated. The grain was conditioned five times in total before drying back to ca. $15 \%$ moisture content.

\subsection{Washing (W) of wheat followed by drying back to $15 \%$ moisture content.}

Grain samples were placed in a cement mixer and water added with a hand-held sprayer until the grain was wet. The grain was placed in bread crates $(40 \times 60 \mathrm{~cm})$ with a perforated base and lined with a hessian sack. The grain was spread evenly over the base to a depth of $7 \mathrm{~cm}$. The grain was washed by overhead sprinklers for 24 hours (irrigation rate was $15 \mathrm{~mm} / \mathrm{min}$ ). The grain was then dried on a hot-air drier until the moisture content was ca. 15\% (ca. 16 hours).

\subsection{Field Experiment 1-Irrigation once ripe/delayed harvest}

Four blocks of two plots of winter wheat, cv. Malacca $(12$ × $2 \mathrm{~m})$ were sown and maintained according to standard farm practice at Harper Adams University. A fungicide program based around triazole chemistry was applied at stem extension (Zadok's Growth Stage 31 [GS31] (Tottman, Makepeace, \& Broad, 1979) ) and flag leaf fully emerged (GS 39). In deviation from standard farm practice, a fungicide at early anthesis (GS 61-65) was not used. The plots were inoculated with a suspension of Fusarium spores $\left(10^{5}\right.$ spores $\left./ \mathrm{ml}, 33 \mathrm{ml} / \mathrm{m}^{2}\right)$ at full ear emergence (GS 59). The spore suspension was a mixture of five isolates of Fusarium culmorum and five isolates of $F$. graminearum. All isolates originated from UK wheat and were known DON and ZON producers. Plots were mist irrigated for five days post-inoculation to stimulate Fusarium head blight. When the crop was ripe (GS 92), one plot within each block was mist irrigated for 30 seconds every 5 minutes each night (01:00 - 05:00) for five days. Plots were harvested two days after the end of the irrigation treatment and dried overnight to ca. $15 \%$ moisture content.

\subsection{Field Experiment 2 - Irrigation during ripening/delayed harvest}

The second field experiment was conducted at Harper Adams University, UK as part of a study on the impact of pre-harvest rainfall on the mycotoxin content of whole grain at harvest and has been published previously. Winter wheat, cv. Solstice, was sown in first week of October and grown according to standard farm practices in Shropshire, UK. The experiment was designed as a split-plot randomized block with twelve treatments replicated four times. Experimental plots (4 x $6 \mathrm{~m}$ ) were separated by guard plots $(6 \times 6 \mathrm{~m})$ and inoculated with $F$. graminearum-infected oat grains $\left(23 \mathrm{~g} \mathrm{~m}^{-}\right.$ $\left.{ }^{2}\right)$ at stem extension (GS31). Fungicide treatment was randomized between split plots while water and harvest treatments were fully randomized between whole plots. All plots were mist irrigated (EinDor Emitters, Tavlit, UK) for $17 \mathrm{~h}$ per day (05.00-22.00 hours) for 5 days from 1 day after the 
135 fungicide was applied to optimize conditions for FHB infection. All guard plots also received a robust

136 fungicide regime containing prothioconazole to minimize the spread of inoculum between treated

137 plots. Water regimes were arranged in a full-factorial design of plots either, covered by small

138 polytunnels $(10 \times 6 \mathrm{~m})$ to mimic dry conditions, irrigated by sprinklers or left as non-irrigated

139 uncovered controls after the mid-milk growth stage (GS75). For irrigated water regime, the sprinkler

140 heads were mounted on raisers at a height of $1.5 \mathrm{~m}$ and allowed to run for $10 \mathrm{~min}$ every $30 \mathrm{~min}$ from

$14122: 00 \mathrm{~h}$ to 10:00 $\mathrm{h}$ every day. This kept the crop wet during the night and dry during the day.

142 Sprinklers were switched off to allow the crop to dry before harvest for four days. Plots were

143 harvested when ripe (GS92; early harvest) and three weeks later (late harvest) using a combine

144 harvester (Wintersteiger Nursery Mater, Austria). Only grain samples collected from the fungicide

145 untreated split-plots were forwarded for milling.

\subsection{Milling and mycotoxin analysis}

148 Samples (6 kg) were delivered to Campden-BRI (Chipping Campden, UK) where the moisture 149 content was measured, cleaned using a Carter-Day dockage tester (weights of screenings and clean 150 wheat recorded), a sample of cleaned wheat (200 g) was reserved and the remainder was conditioned

151 to $16 \%$ moisture content and milled using a Buhler Mill with a standard setting for high starch

152 damage/hard wheats. The samples were milled in order of expected mycotoxin contamination (lowest

153 first) and clean wheat was passed through the mill between each sample to minimize cross-

154 contamination of samples within the mill. Bran and Offal fractions were cleaned in a Buhler

155 Laboratory Impact Finisher. The resulting mill fractions were: screenings, cleaned grain, break flour,

156 reduction flour, bran, offal, bran finisher flour and offal finisher flour. Bran is coarse cleaned bran

157 separated from break flour after the break rollers. Offal is a mixture of germ and fine bran (mainly

158 fine bran) which is separated from reduction flour after the reduction rollers. Finisher flours are 159 produced during the cleaning of the bran and offal fractions.

160 For the laboratory experiments and the first field experiment each fraction was weighed, mixed,

161 sub-samples collected (200 g or total fraction if less than $200 \mathrm{~g}$ in weight) and delivered to Fera

162 Science Ltd for trichothecene analysis by GC-MS (LoQ $=20 \mu \mathrm{g} \mathrm{kg}^{-1}$ ) using a UKAS accredited

163 method. The expanded measurement of uncertainty was $12 \%$ for DON. For the second field

164 experiment each fraction was weighed before fractions were combined to form three mill fractions

165 SRF (straight run flour from the break and reduction fractions), bran (cleaned bran) and offal (cleaned

166 offal, bran finishing flour and offal finishing flour). These fractions were thoroughly mixed before

167 laboratory sub-samples were collected (200 g or total fraction if less than $200 \mathrm{~g}$ in weight) and

168 analyzed for DON and ZON using Enzyme Linked Immunosorbent Assays (ELISA) following the

169 manufacturer's instructions given in Ridascreen ${ }^{\circledR}$ DON and ZON immunoassay kits (R-Biopharm

170 Rhone Ltd, Glasgow, UK). 


\subsection{Statistical analysis}

All mycotoxin concentrations were adjusted to a moisture content of $16 \%$. All statistical analysis was completed with Genstat (version 13, VSN International). All concentrations were logarithmically transformed to normalize the residuals. To determine recovery of mycotoxin in milling fractions, mass balance calculations were performed to compare the calculated grain mycotoxin content from the combined mycotoxin content of mill fractions to the content of the cleaned grain by paired t-tests and regression analysis. The mycotoxin content of each mill fraction was calculated as the percentage of the cleaned grain mycotoxin concentration to give a relative distribution of DON within mill fractions before and after treatment. For ANOVA a factorial splitplot design was used with mill fraction as the sub-plot. Significant differences between individual samples were determined using the Bonferroni test $(\mathrm{P}<0.05)$.

\section{Results}

\section{Mass balance analysis}

Paired t-tests identified there was no significant difference $(\mathrm{p}=0.96)$ in the mycotoxin content of break flour and reduction flour. The content of these two flours were combined and referred to as Straight Run Flour (SRF). Mass balance analysis showed a strong correlation between the predicted DON and ZON concentrations for cleaned grain based on the sum of the mill fraction contents and the measured DON and ZON concentrations for cleaned grain with no significant differences. As an example, Figure 1 shows the regression analysis for DON from the in vitro experiments and the first field experiment. The line of best fit has a gradient close to one when forced through the origin and a correlation co-efficient of 0.95 . These results indicate that there was no loss or gain of DON or ZON during milling. The results also provide quality assurance to the mycotoxin results as they indicate that the mycotoxin concentrations for the mill fractions and the respective cleaned grains are all in agreement with one another.

All wheat samples used in the in vitro experiments were from the 2005 harvest with a DON concentration ranging from 355 to $5688 \mu \mathrm{g} \mathrm{kg}^{-1}$ (Table 1). Nivalenol and zearalenone were also detected but not in sufficient concentrations in all mill fractions to permit statistical analysis.

\subsection{Laboratory water experiments}

The DON concentration of cleaned grain and each mill fraction (bran, offal and SRF) for the repeated conditioning and the wash treatment are presented in Figure 2a. The DON concentration 
and the DON content of each mill fraction as a percentage of the cleaned grain DON concentration was analyzed for each experiment by factorial (Time x Fraction) ANOVA. All analysis showed significant interactions $(\mathrm{P}<0.05)$. Prior to the treatments the DON concentration in mill fractions were as reported previously for wheat harvested in the UK in 2005 (Kharbikar, Dickin, \& Edwards, 2015) with lower DON concentrations in the SRF and more in the bran and offal fractions (Figure 2a). There was little change in the concentration of DON in cleaned grain, SRF and bran but a significant reduction (40\%) in DON in the offal fraction occurred after repeated conditioning. There were much greater differences after washing the grain. The DON concentration of washed grain 212 dropped 2.4-fold, 1.8-fold in SRF and ca. 7-fold for bran and offal (Figure 2a). As the reduction in 213 SRF was less than that of the cleaned grain then the DON content of SRF as a percentage of the cleaned grain concentration actually increased (Figure 2b).

\subsection{Field Experiment 1 - Mist irrigation once ripe/delayed harvest}

There was no significant difference $(\mathrm{p}=0.597)$ in the DON concentration of the harvested cleaned grain from wet (mist irrigated) and dry (control) plots (787 and $820 \mu \mathrm{g} \mathrm{kg}^{-1}$ respectively). The DON content of mill fractions from each plot was calculated as a percentage of the cleaned grain DON concentration (Figure 3). Analysis of variance revealed a significant interaction $(\mathrm{p}=0.049)$ between water treatment and mill fractions. Although there were no significant differences between the content of each mill fraction for Wet and Dry plots the percentage of DON in bran and offal was lower whilst the percentage of DON in SRF was higher in the wet plots.

\subsection{Field Experiment 2 - Irrigation during ripening/delayed harvest}

Absolute DON concentrations and DON as a percentage of the cleaned grain concentration were analyzed by factorial (water treatment $\mathrm{x}$ harvest timing $\mathrm{x}$ mill fraction) ANOVA. There was a significant three-way interaction between all factors $(\mathrm{P}=0.048)$. Back-transformed averages are presented in Figure 4a with the cleaned grain values included for comparison. Results showed significantly higher DON in most bran and offal fractions with few significant differences between water regimes for each harvest timing and mill fraction. There was a significantly higher DON concentration in SRF and offal in irrigated compared with covered plots following a late harvest.

For DON concentrations as a percentage of the cleaned grain DON concentration within mill

234 fractions harvest timing and interactions including harvest timing were not significant $(\mathrm{P}>0.05)$.

235 There was a significant interaction $(\mathrm{P}<0.001)$ between water treatment and fraction (Figure $4 \mathrm{~b}$ ). The

236 proportion of DON in SRF was significantly lower than in bran and offal and the proportion of DON

237 within the bran fraction was significantly lower in the irrigated plots compared to the covered and 238 control plots. 
ZON was quantified in all bran and offal fractions but only occurred above the LoQ $(1.75 \mu \mathrm{g} \mathrm{kg}$ -

$240{ }^{1}$ ) in the SRF from the irrigated plots. Factorial ANOVA (harvest time $\mathrm{x}$ mill fraction) was conducted

241 on the irrigated plots for all mill fractions both as absolute concentrations and as percentages of the

242 cleaned grain concentration. For both analyses there were no significant interactions. There was a

243 significant $(\mathrm{p}=0.014$ ) difference of harvest time with ca. 2-fold higher $\mathrm{ZON}$ with a late compared with

244 early harvest for the absolute concentrations but no difference $(p=0.259)$ in the distribution of ZON

245 between the mill fractions for the two harvest timings. There were highly significant $(\mathrm{p}<0.001)$

246 differences in the absolute ZON concentrations and the percentage distributions between the mill

247 fractions with the proportion in SRF been $16 \%$ for the cleaned grain concentration and ca. $300 \%$ for

248 the bran and offal fractions (Figure 5). Absolute values and percentage distribution values for ZON

249 concentration within the bran and offal fractions were analyzed by factorial ANOVA (water treatment

$250 \mathrm{x}$ harvest time $\mathrm{x}$ mill fraction). Results were as reported for the irrigated plots alone with no

251 interactions and no significant difference between bran and offal $(\mathrm{p}=0.264)$ and a 2 -fold higher ZON

252 after a later harvest $(\mathrm{p}=0.034)$. For the water treatments, differences were highly significant

253 ( $\mathrm{p}<0.001)$ for absolute ZON concentrations with much higher ZON present after the irrigation

254 treatment (Figure 6). Non-irrigated treatments averaged $3 \mu \mathrm{g} \mathrm{kg}^{-1}$ whilst irrigated plots were over 20-

255 fold higher at $65 \mu \mathrm{g} \mathrm{kg}^{-1}$. For the percentage distribution data there were no significant differences

256 between fractions, harvest timings or water treatments $(p>0.1)$.

\section{Discussion}

The general consensus is that mycotoxins are not broken down or metabolized during milling

261 (as reviewed by Cheli, et al., 2013 and Kushiro, 2008) and as such the sum content of the mill fractions

262 should match the content of the cleaned grain sample prior to milling. Mass balance analysis of

263 mycotoxin concentration of cleaned grain and the sum of the mill fractions contents as reported in

264 this study are a useful quality assurance check and should be used routinely within milling 265 experiments.

266 The studies in this paper aimed to explore the impact of water post-anthesis with two extreme 267 laboratory studies to mimic firstly the repeated drying and wetting of grain which can occur when 268 harvests are delayed due to intermittent rainfall and the washing of grain by sprinkler irrigation that 269 mimicked a period of extended heavy rainfall. These experiments were followed by field experiments 270 which mimicked repeated wetting and rainfall events with misting and sprinkler irrigation.

271 The repeated conditioning treatment did not result in a significant increase or decrease in DON 272 concentration of cleaned wheat. Although there was only a significant difference for the percentage 273 DON in the offal fraction after conditioning it could be seen that there was a trend for conditioning 274 to result in a shift in all fractions towards the cleaned wheat concentration. The first field experiment 
with five days of overnight mist irrigation showed the same trend as the laboratory experiment with repeated conditioning. This would suggest that repeated wetting and drying of grains results in movement of DON within the grains until equilibrium is reached. This would explain why previous studies have identified a wide range of the DON as a proportion of the cleaned grain concentration in white flour fractions (Cheli, et al., 2013; Kushiro, 2008) and higher variation exists in temperate climates with more variable climate during cereal ripening (Edwards, et al., 2011).

The washing treatment resulted in a considerable reduction of DON in the cleaned grain and all mill fractions. It has previously been shown that post-anthesis rainfall can result in a reduction of DON in grain (Gautam \& Dill-Macky, 2012a; Kharbikar, et al., 2015). Gautam and Dill-Macky (2012b) proposed that post-anthesis rainfall resulted in a reduction of DON in field experiments and later confirmed that rainfall can leach DON directly from Fusarium infected plants and showed reductions of up to $50 \%$ after $133 \mathrm{~mm}$ of sprinkler irrigation in a glasshouse study (Gautam \& DillMacky, 2012a). It can be expected that any leaching of DON from grain would occur most from the seed coat, which is a major constituent of the bran and offal fractions. The highest reduction of DON within the mill fractions corresponded to bran, followed by offal and SRF. Consequently the relative distribution of DON within the three fractions was lowest in SRF before washing to highest in SRF after washing. The second field experiment had significantly higher DON in the cleaned grain in the irrigated plots (Kharbikar, et al., 2015). Differences in mill fractions were not as clear cut with a significant increase in DON concentration in SRF and offal with irrigation but not for bran after a late harvest. The overall trend for the distribution of DON in mill fractions was the same as the other experiments with irrigation resulting in a higher proportion of DON in the SRF and lower proportion within the bran fraction. Studies of wheat grain after harvest have shown DON can increase or decrease as a result of post-anthesis rainfall (Cowger, Patton-Ozkurt, Brown-Guedira, \& Perugini, 2009; Gautam \& Dill-Macky, 2012b) and differences reported are probably related to the timing and level of rainfall occurring so that in some scenarios DON production can occur due to elevated moisture content within grains and in others, leaching of DON occurs and as such the DON concentration is in flux. The experimental results from this study confirms the hypothesis developed

302 from the previous observational study (Edwards, et al., 2011) that the distribution of DON within mill 303 fractions is not stable and will vary between seasons and regions depending on post-anthesis rainfall. 304 In a previous study, higher ZON concentrations recorded in UK wheat in 2004 and 2008 was thought to be due to the delayed wet harvests and it was shown that $\mathrm{ZON}$ is more problematic after delayed wet harvests compared to DON (Edwards, 2009, 2011). Observational data indicated that ZON concentration increases greatly during ripening of wheat due to rainfall (Edwards, 2011). The

308 previous study (Kharbikar, et al., 2015) where ZON was analyzed in the whole grain showed ZON 309 production was dependent on post-anthesis rainfall even when wheat was heavily contaminated with 310 F. graminearum. Sporadic data is available on the distribution of ZON within mill fractions due to 311 the low incidence and levels at which this mycotoxin often occurs. However, ZON was quantifiable 
312 in many of the samples in the second field experiment. Data from the irrigated plots showed ZON

313 was much higher in the bran and offal fractions compared with the SRF as per previous observational

314 studies (Edwards et al., 2011; Trigo-Stockli et al., 1996). The distribution of ZON in the bran and

315 offal fractions was not affected by water treatments or harvest timing indicating this mycotoxin does

316 not move between grain fractions and is not leached from the grain. As such the proportion of ZON

317 within the mill fractions is stable across seasons and regions. This is probably due to the low solubility

318 of ZON in water (Karlovsky, et al., 2016). Although, the unprocessed cleaned grain and SRF from

319 the second experiment were within legislative limits for DON and ZON, offal and bran with mean

320 DON levels higher than $750 \mu \mathrm{g} \mathrm{kg}^{-1}$ and mean ZON levels greater than $75 \mu \mathrm{g} \mathrm{kg}^{-1}$ particularly in

321 irrigated plots indicate that offal and bran obtained from late harvested wheat crops after post-anthesis

322 rainfall cannot be utilized as end product for direct human consumption without mycotoxin testing to

323 ensure they conform to legislative limits.

324 Wheat production occurs across many regions of the world including temperate climates where

325 the grain ripening and harvesting can be delayed due to wet weather. Results from this study have

326 identified that wet weather during this period not only impacts on the concentration of fusarium

327 mycotoxins within harvested grains, but can also alter the distribution of some mycotoxins within the

328 mill fractions. It is imperative that processors of cereals understand the distribution of fusarium

329 mycotoxins within mill fractions and how this distribution can vary to avoid exceeding mycotoxin

330 legal limits for intermediate and finished products.

\section{Conclusions}

The results show that DON is highly mobile within grain and can migrate between grain structures and be leached from the grain pre-harvest resulting in varying distributions across mill

335 fractions post-harvest. Less data is available for ZON but results show that $\mathrm{ZON}$ is not mobile within 336 the grain and the distribution of ZON between mill fractions is less variable.

\section{Acknowledgments}

339 This research was funded by grants from the Food Standards Agency (C03041) and the Defra 340 Food Quality and Safety LINK Programme (FQS64) and a PhD studentship funded by Bayer 341 CropSciences and Harper Adams University. All grain was milled by Dereck Buttler at Campden 342 BRI.

\section{References}


Brera, C., Peduto, A., Debegnach, F., Pannunzi, E., Prantera, E., Gregori, E., De Giacomo, M., \& De Santis, B. (2013). Study of the influence of the milling process on the distribution of deoxynivalenol content from the caryopsis to cooked pasta. Food Control, 32(1), 309-312.

Cheli, F., Pinotti, L., Rossi, L., \& Dell'Orto, V. (2013). Effect of milling procedures on mycotoxin distribution in wheat fractions: A review. Lwt-Food Science and Technology, 54(2), 307-314.

Cowger, C., \& Arellano, C. (2013). Fusarium graminearum Infection and Deoxynivalenol Concentrations During Development of Wheat Spikes. Phytopathology, 103(5), 460471.

Cowger, C., Patton-Ozkurt, J., Brown-Guedira, G., \& Perugini, L. (2009). Post-Anthesis Moisture Increased Fusarium Head Blight and Deoxynivalenol Levels in North Carolina Winter Wheat. Phytopathology, 99(4), 320-327.

EC. (2006). Commission Regulation (EC) No 1881/2006 of 19 December 2006 setting maximum levels for certain contaminants in foodstuffs. Official Journal of the European Union, L364, 5-24.

Edwards, S. G. (2009). Fusarium mycotoxin content of UK organic and conventional wheat. Food Additives and Contaminants Part A-Chemistry Analysis Control Exposure \& Risk Assessment, 26(4), 496-506.

Edwards, S. G. (2011). Zearalenone risk in European wheat. World Mycotoxin Journal, 4(4), 433-438.

Edwards, S. G., Dickin, E. T., MacDonald, S., Buttler, D., Hazel, C. M., Patel, S., \& Scudamore, K. (2011). Distribution of Fusarium mycotoxins in UK wheat mill fractions. Food Additives \& Contaminants, 28, 1694-1704.

Fernandes, P. J., Barros, N., Santo, J. L., \& Camara, J. S. (2015). High-Throughput Analytical Strategy Based on Modified QuEChERS Extraction and Dispersive Solid-Phase Extraction Clean-up Followed by Liquid Chromatography-Triple-Quadrupole Tandem Mass Spectrometry for Quantification of Multiclass Mycotoxins in Cereals. Food Analytical Methods, 8(4), 841-856.

Gautam, P., \& Dill-Macky, R. (2012a). Free Water Can Leach Mycotoxins from Fusariuminfected Wheat Heads. Journal of Phytopathology, 160(9), 484-490.

Gautam, P., \& Dill-Macky, R. (2012b). Impact of moisture, host genetics and Fusarium graminearum isolates on Fusarium head blight development and trichothecene accumulation in spring wheat. Mycotoxin research, 28, 45-58.

Karlovsky, P., Suman, M., Berthiller, F., De Meester, J., Eisenbrand, G., Perrin, I., Oswald, I. P., Speijers, G., Chiodini, A., Recker, T., \& Dussort, P. (2016). Impact of food processing and detoxification treatments on mycotoxin contamination. Mycotoxin research, 32(4), 179-205.

Kharbikar, L. L., Dickin, E. T., \& Edwards, S. G. (2015). Impact of post-anthesis rainfall, fungicide and harvesting time on the concentration of deoxynivalenol and zearalenone in wheat. Food Additives \& Contaminants: Part A, 32(12), 2075-2085.

Kushiro, M. (2008). Effects of milling and cooking processes on the deoxynivalenol content in wheat. International Journal of Molecular Sciences, 9(11), 2127-2145.

Moretti, A., Panzarini, G., Somma, S., Campagna, C., Ravaglia, S., Logrieco, A. F., \& Solfrizzo, M. (2014). Systemic Growth of F. graminearum in Wheat Plants and Related Accumulation of Deoxynivalenol. Toxins, 6(4), 1308-1324.

Savi, G. D., Piacentini, K. C., Tibola, C. S., Santos, K., Maria, G. S., \& Scussel, V. M. (2016). Deoxynivalenol in the wheat milling process and wheat-based products and daily intake estimates for the Southern Brazilian population. Food Control, 62, 231-236. 
Schwake-Anduschus, C., Proske, M., Sciurba, E., Muenzing, K., Koch, M., \& Maul, R. (2015). Distribution of deoxynivalenol, zearalenone, and their respective modified analogues in milling fractions of naturally contaminated wheat grains. World Mycotoxin Journal, 8(4), 433-443.

Scudamore, K. A., Hazel, C. M., Patel, S., \& Scriven, F. (2009). Deoxynivalenol and other Fusarium mycotoxins in bread, cake, and biscuits produced from UK-grown wheat under commercial and pilot scale conditions. Food Additives and Contaminants Part A-Chemistry Analysis Control Exposure \& Risk Assessment, 26(8), 1191-1198.

Scudamore, K. A., \& Patel, S. (2008). The fate of deoxynivalenol and fumonisins in wheat and maize during commercial breakfast cereal production. World Mycotoxin Journal, $1(4), 437-448$.

Thammawong, M., Okabe, M., Kawasaki, T., Nakagawa, H., Nagashima, H., Okadome, H., Nakajima, T., \& Kushiro, M. (2010). Distribution of deoxynivalenol and nivalenol in milling fractions from fusarium-infected Japanese wheat cultivars. Journal of Food Protection, 73(10), 1817-1823.

Thammawong, M., Okadome, H., Shiina, T., Nakagawa, H., Nagashima, H., Nakajima, T., \& Kushiro, M. (2011). Distinct Distribution of Deoxynivalenol, Nivalenol, and Ergosterol in Fusarium-infected Japanese Soft Red Winter Wheat Milling Fractions. Mycopathologia, 172(4), 323-330.

Tibola, C. S., Fernandes, J. M. C., Guarienti, E. M., \& Nicolau, M. (2015). Distribution of Fusarium mycotoxins in wheat milling process. Food Control, 53, 91-95.

Tottman, D. R., Makepeace, R. J., \& Broad, H. (1979). An explanation of the decimal code for the growth stages of cereals, with illustrations. Annals of Applied Biology, 93(2), 221-234.

TrigoStockli, D. M., Deyoe, C. W., Satumbaga, R. F., \& Pedersen, J. R. (1996). Distribution of deoxynivalenol and zearalenone in milled fractions of wheat. Cereal Chemistry, 73(3), 388-391.

Zhang, H. J., \& Wang, B. J. (2014). Fate of deoxynivalenol and deoxynivalenol-3-glucoside during wheat milling and Chinese steamed bread processing. Food Control, 44, 8691.

Zheng, Y. Z., Hossen, S. M., Sago, Y., Yoshida, M., Nakagawa, H., Nagashima, H., Okadome, H., Nakajima, T., \& Kushiro, M. (2014). Effect of milling on the content of deoxynivalenol, nivalenol, and zearalenone in Japanese wheat. Food Control, 40, 193-197. 


\section{Table 1}

433 Details of selected wheat samples. $\mathrm{C}=$ used in the repeated conditioning experiment; $\mathrm{W}=$ used in 434 the washing experiment. Mycotoxin results are $\mu \mathrm{g} \mathrm{kg}^{-1}$. All other trichothecenes analysed were either 435 low or absent. NABIM group is the milling quality of the variety; 1 are bread wheats with a hard 436 endosperm, 3 are biscuit wheats with a soft endosperm.

437

\begin{tabular}{llccccc}
\hline Sample No. & Variety & NABIM & $\begin{array}{l}\text { Specific } \\
\text { Weight }\end{array}$ & DON & NIV & ZON \\
\hline C FQS/05/03 & Claire & 3 & 63.3 & 2014 & 141 & 504 \\
C FQS/05/10 & Paragon & 1 & 72.4 & 1161 & 138 & 86 \\
C FQS/05/18 & Xi19 & 1 & 73.1 & 416 & 165 & 18 \\
C FQS/05/19 & Malacca & 1 & 74.1 & 355 & 162 & 12 \\
W FQS/05/09 & Xi19 & 1 & 76.7 & 548 & $<20$ & 11 \\
W FQS/05/11 & Deben & 3 & 72.7 & 418 & $<20$ & $<5$ \\
W FQS/05/12 & Nijinsky & 3 & 69.2 & 5688 & 179 & $<5$ \\
W FQS/05/16 & Deben & 3 & 76.4 & 406 & 149 & 7 \\
\hline
\end{tabular}

438

439

440

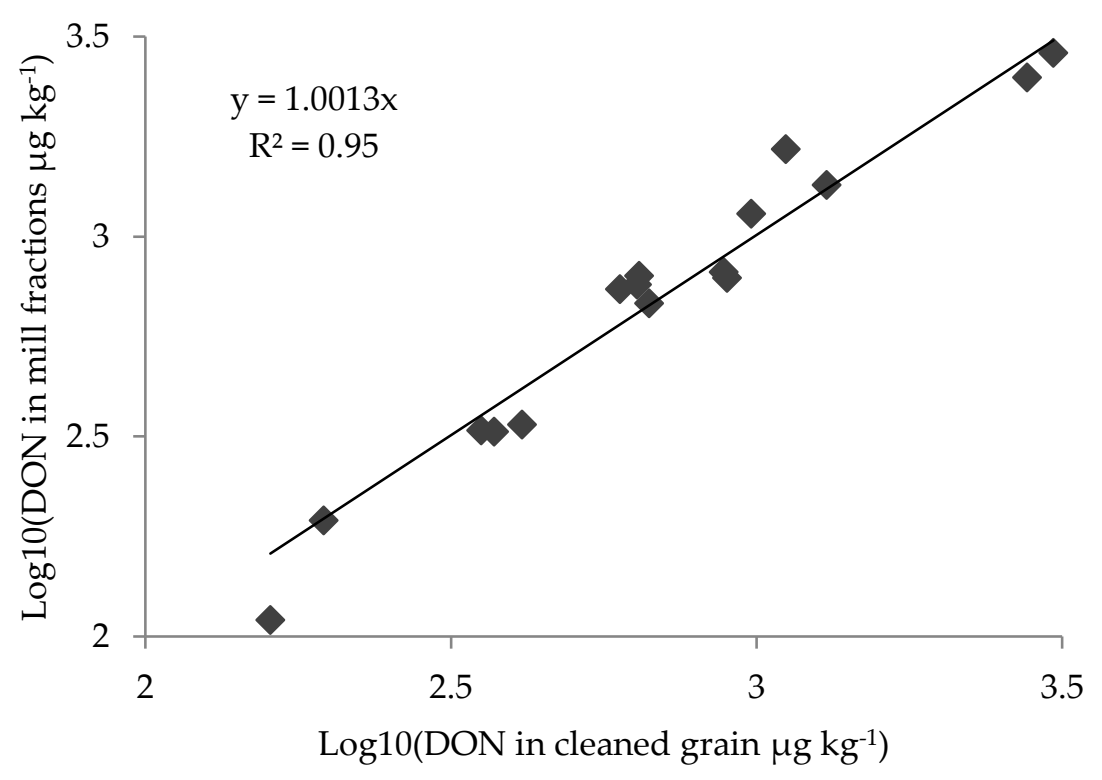

442 Fig 1. Regression plot of the calculated DON concentration of cleaned grain based on the sum of the 443 mill fractions against the actual DON concentration in cleaned grain (log-log plot). 


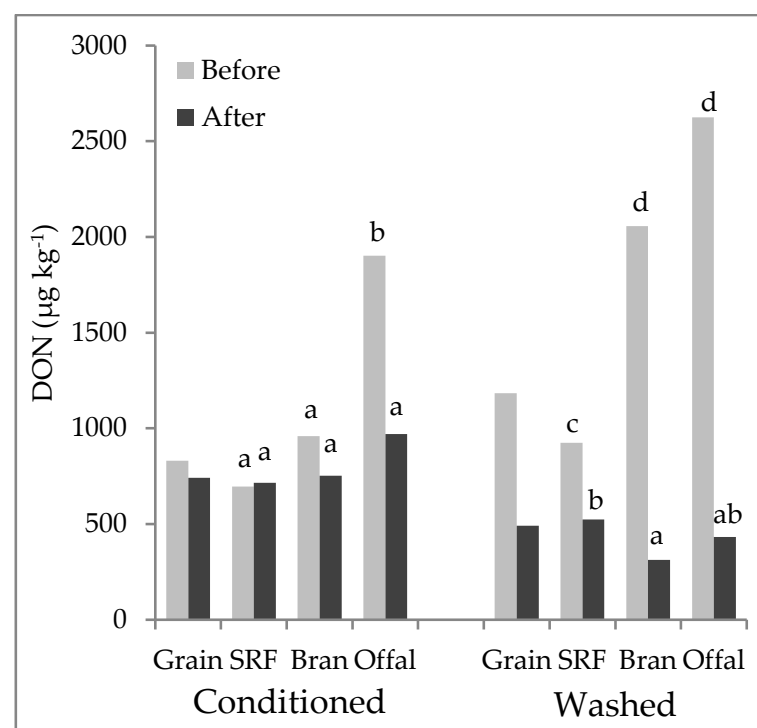

(a)

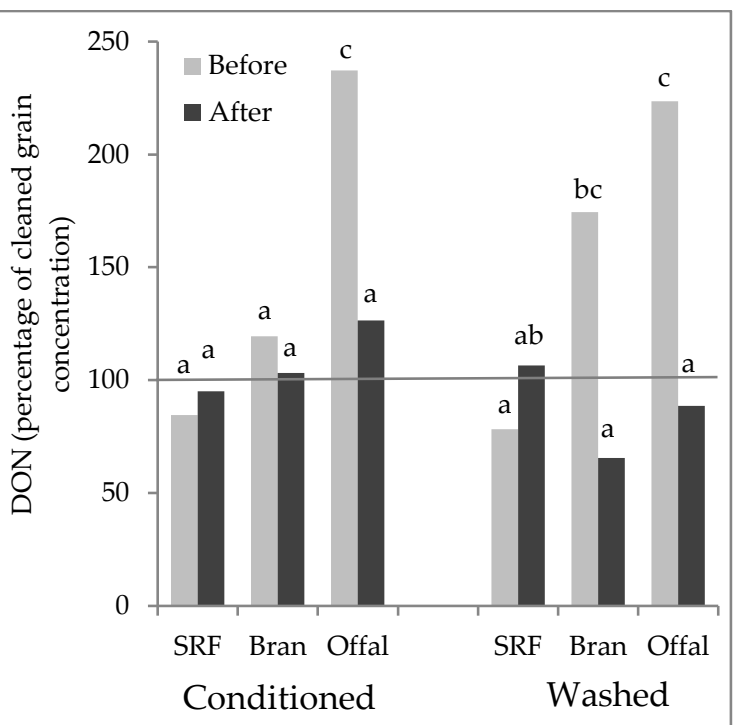

(b)

Fig 2. (a) Back-transformed mean DON concentration of cleaned grain and mill fractions before and after repeated conditioning and washing (b) Back-transformed mean DON content of mill fractions as a percentage of the cleaned grain concentration before and after repeated conditioning and washing treatments $(n=4)$. Columns within each treatment followed by the same letter are not significantly different (Bonferroni test, $\mathrm{p}<0.05$ ). Cleaned grain is included for comparison but was not included in the analysis. SRF, Straight Run Flour.

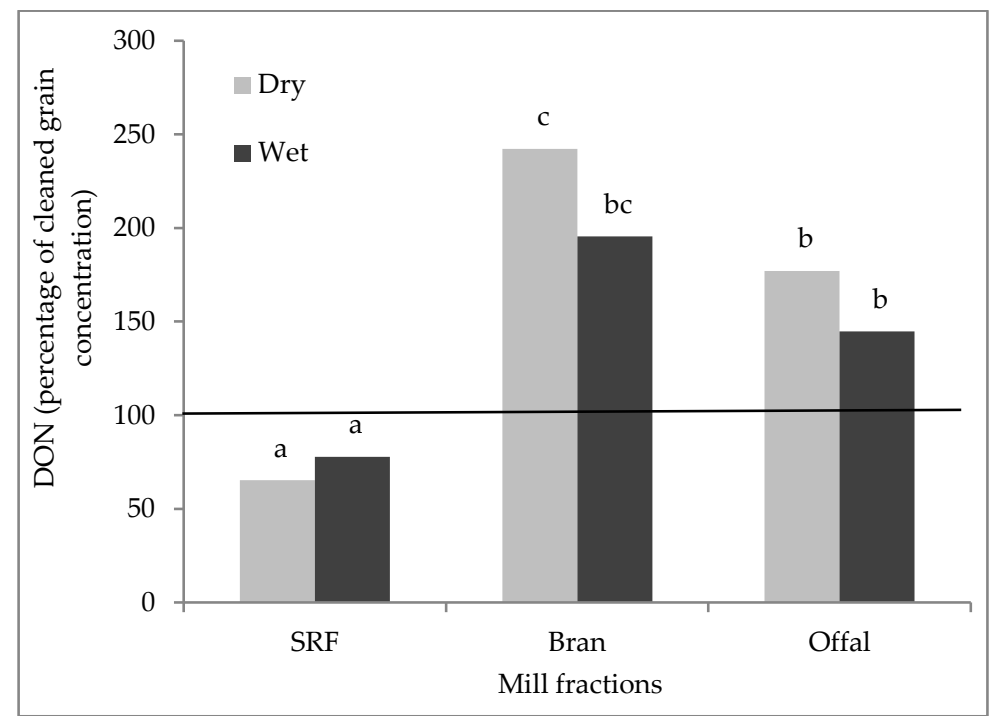

Fig 3. Mean DON content of mill fractions as a percentage of the cleaned grain concentration from control wheat plots and plots mist irrigated for 5 days before harvest. SRF, Straight Run Flour. 

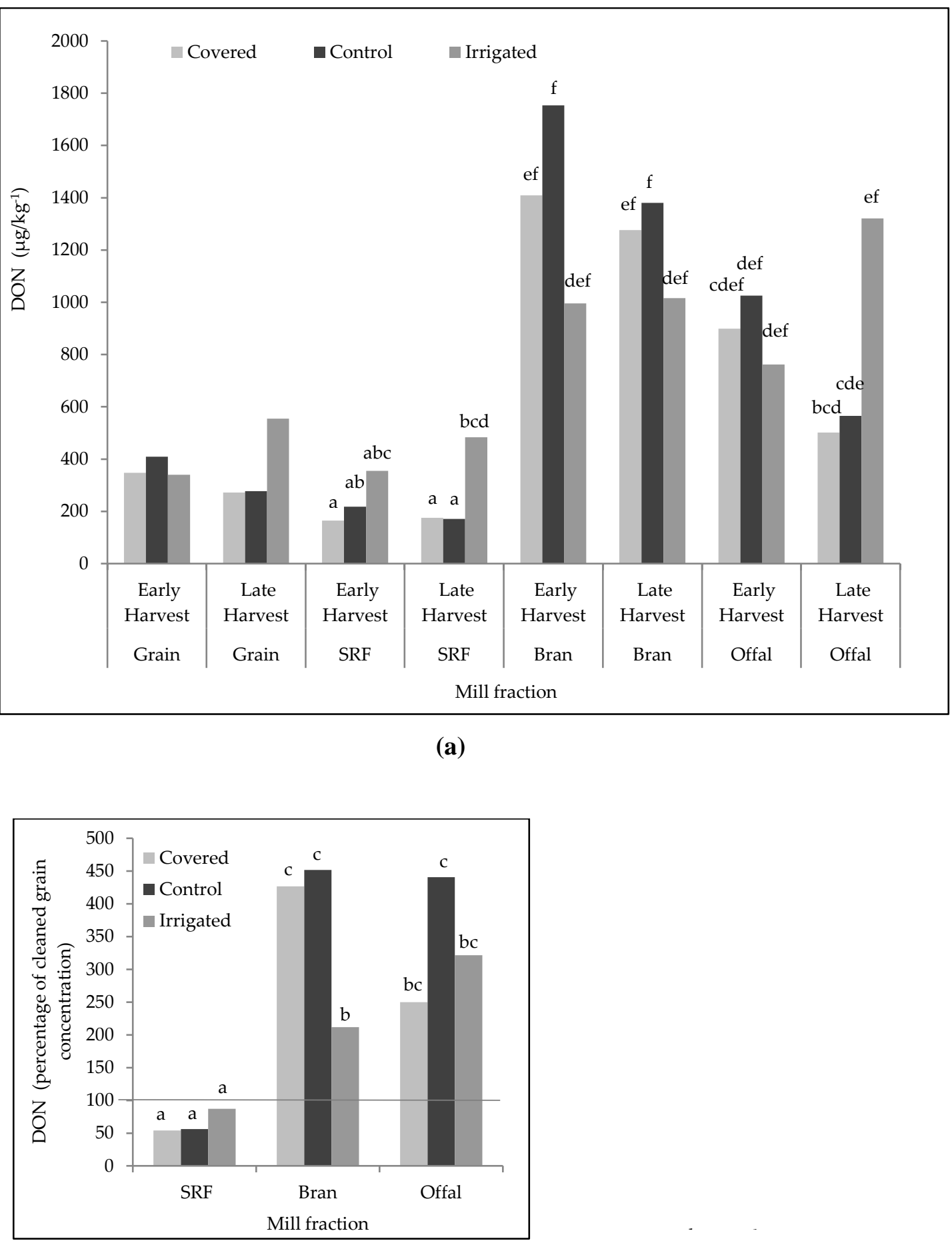

(b)

467 Fig 4. (a) Back-transformed mean DON concentration of cleaned grain and mill fractions from the 468 second field experiment with different water treatments during ripening and with an early and late harvest. Cleaned grain is included for comparison but was not included in the analysis. (b) Backtransformed mean DON content of mill fractions as a percentage of the cleaned grain concentration

471 for each mill fraction and water treatment. Columns followed by the same letter are not significantly 472 different (Bonferroni test, $\mathrm{p}<0.05$ ). SRF, Straight Run Flour. 
475

476

477

478
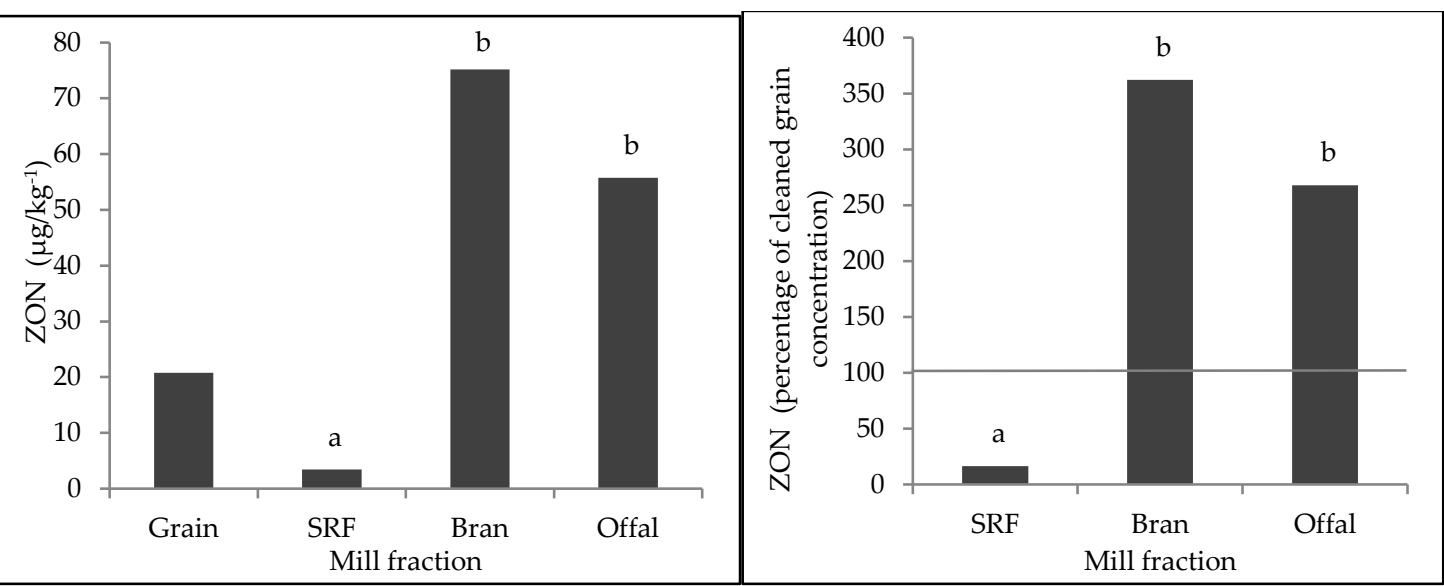

(a)

(b)

Fig 5. (a) Back-transformed mean $\mathrm{ZON}$ concentration of cleaned grain and mill fractions from the second field experiment irrigated plots. Cleaned grain is included for comparison but was not included in the analysis. (b) Back-transformed mean ZON content of mill fractions as a percentage of the cleaned grain concentration for each mill fraction. Columns followed by the same letter are not significantly different (Bonferroni test, $\mathrm{p}<0.05$ ). SRF, Straight Run Flour. 